\title{
Sorption of aspartic and glutamic aminoacids on calcined hydrotalcite
}

\author{
Fabiano Silvério ${ }^{1}$, Márcio José dos Reis ${ }^{1,2^{*}}$, Jairo Tronto ${ }^{1}$ and João Barros Valim
}

\begin{abstract}
Sorption of aspartic and glutamic aminoacids by regeneration of calcined hydrotalcite is reported. Hydrotalcite was synthesized by coprecipitation and calcined at $773 \mathrm{~K}$. Sorption experiments were performed at $298 \mathrm{~K}$ and $310 \mathrm{~K}$, and the results reveal that at low aminoacids equilibrium concentrations, intercalation of hydroxyl anions takes place while at high equilibrium concentrations, the sorption process occur by means re-hydration and aminoacids intercalation of hydrotalcite. The results also suggested that Asp and Glu sorption is a temperature dependent process. The amount of sorbed amino acid decreases as the temperature increase. The effect is more pronounced for Glu sorption probably due to its higher hydrophobic character, which makes the sorption more difficult in comparison with sorption of Asp at higher temperature.
\end{abstract}

Keywords: Hydrotalcite, Layered double hydroxides, Aminoacids, Adsorption, Sorption

\section{Introduction}

Hydrotalcite-like compounds, also known as Layered Double Hydroxides (LDH) have received considerable attention due to their properties and applications (Costantino et al. 2008; Takehira \& Shishido 2007; Darder et al. 2007; Evans \& Xue 2006; Velu et al. 2005; Anbarasan et al. 2005; Zhu et al. 2005; Tronto et al. 2004). Their structure consists of sheets disposed in a layered array formed by octahedral sharing their edges, with bi and trivalent cations on the centers of octahedral hexacoordinated with hydroxyl anions. Layers of LDH are residual positive charge neutralized by anions located in the interlayer domain.

Hydrotalcite can be used to remove anions from aqueous solution by three different processes: adsorption, anion exchange and regeneration of a calcined precursor (Zhu et al. 2005; Takehira et al. 2005; Aisawa et al. 2004). $\mathrm{Mg}$-Al and $\mathrm{Zn}$-Al LDH systems present the specific property known "memory effect" that consists in the capacity of calcined LDH regenerate its lamellar structure by incorporation of anions when it is put in contact with an intercalating anion in aqueous solution

\footnotetext{
* Correspondence: reis.mj@gmail.com

1 Departamento de Química - Faculdade de Filosofia Ciências e Letras de Ribeirão Preto, Universidade de São Paulo, Av. Bandeirantes, 3900, CEP 14040-901, Ribeirão Preto, Brazil

${ }^{2}$ Present Address: Universidade de Franca, Av. Dr. Armando Salles Oliveira, 201, Parque Universitário, CEP14404-600, Franca, SP, Brazil
}

(Kooli et al. 1997). Taking advantage of the "memory effect", different molecules such as polyorganic anions, benzoate, tereftalate and surfactants, have been sorbed onto LDH (Cardoso et al. 2003; Cardoso et al. 2004; Crepaldi et al. 2002).

Aspartic (Asp) and glutamic (Glu) aminoacids are used in pharmaceutical and food industry, where industrial wastewater treatment is not often practiced (Ohtsubo et al. 2005; Shih \& Van 2001). These aminoacids differ due to an extra $\mathrm{CH}_{2}$ group in the Glu aliphatic chain and both have a carboxylic group. This work is focused on evaluation of sorption process of Asp and Glu aminoacids by regeneration of calcined MgAl-LDH in order to verify the efficiency of its adsorbent for wastewaters treatment.

\section{Materials and methods}

\section{Layered double hydroxide - the sorbent}

The LDH was prepared by coprecipitation at variable pH as proposed by Reichle (Reichle et al. 1986). All reactants were of analytical grade and were used without further purification. Magnesium Nitrate ( $>99 \%)$, Aluminum Nitrate $(>98 \%)$, Sodium Hydroxide $(>98 \%)$ and Sodium Carbonate ( $>99 \%)$ were purchased from Merck. All solids were characterized by Powder X-Ray Diffraction (PXRD), using a Siemens D5005 X-ray Diffractometer, with a graphite monochromator selecting the $\mathrm{Cu}-\mathrm{K} \alpha_{1}$

\section{实}


radiation $(0.15406 \mathrm{~nm})$ in an angular $2 \theta$ range of $2-70^{\circ}$ and step rate of $0.02^{\circ} \mathrm{s}^{-1}$; Fourier Transform Infra-Red Spectroscopy (FT-IR), with an ABB Bomem MB 100 spectrometer over the range 400-4000 $\mathrm{cm}^{-1}$ with 32 scans and a $4 \mathrm{~cm}^{-1}$ resolution, using pressed $\mathrm{KBr}$ pellets at $2 \%(\mathrm{w} / \mathrm{w})$ of sample; Thermogravimetric and Differential Thermal Analysis (TGA/DTA), using a TA Instruments SDT 2960 in synthetic air atmosphere at a heating rate of $10 \mathrm{~K} \mathrm{~min}{ }^{-1}$; Scanning Electron Microscopy (SEM) using a Zeiss DSM 960-Digital Scanning Microscope; and Specific Surface Area (SSA) performed on Quanta Chrome Nova 1200 equipment.

From TGA/DTA and elemental analysis the formula of the LDH precursor was obtained as $\left[\mathrm{Mg}_{0.7} A l_{0.3}(\mathrm{OH})_{2}\right]^{0.3+}$ $\left(\mathrm{CO}_{3}\right)_{0.15}^{2-} \cdot 0.7 \mathrm{H}_{2} \mathrm{O}$, which corresponds to a $\mathrm{Mg} / \mathrm{Al}$ ratio of $2.3 / 1$. This information is extremely important because the anionic exchange by regeneration depends on of this ratio. Immediately before use in adsorption, the LDH precursor was calcined at $773 \mathrm{~K}$ for 4 hours under $\mathrm{O}_{2}$ (White Martins) flow giving rise a $\mathrm{Mg}$ - $\mathrm{Al}$ mixed oxy-hydroxide the adsorbent.

\section{Aspartic and glutamic acids - the sorbates}

The aminoacids (Asp and Glu) were acquired from Merck (>99.5\% assay), and used without further purification. All aminoacids solutions were prepared with deionized water $\left(\mathrm{MilliQ}^{\circ}\right)$, and the $\mathrm{pH}$ was adjusted to 10 with $\mathrm{NaOH}$.

\section{Adsorption/sorption experiments}

Sorption experiments of Asp and Glu were carried out in bath method with $100 \mathrm{mg}$ of the calcined precursor into $25 \mathrm{~cm}^{3}$ of amino acid solutions at different concentrations (concentration ranging from 0.001 to $0.04 \mathrm{~mol}$. $\mathrm{dm}^{-3}$ for Asp, and from 0.001 to $0.06 \mathrm{~mol}^{-\mathrm{dm}^{-3}}$ for Glu) at $\mathrm{pH}$ 10. The obtained suspension was ultra-sonicated for 10 minutes to homogenize particle size, before adsorption. The isotherms were obtained at $298 \mathrm{~K}$ and $310 \mathrm{~K}$.

Closed samples were place in a thermostatic bath with orbital shaking, for 70 hours, to ensure that the sorption equilibrium would be reached. After that, each sample was divided into two parts: one was centrifuged at $10,000 \mathrm{G}$ for 20 minutes and the supernatant was used to quantifier the amount of amino acid, using a UV-vis 8453 Hewlett Packard spectrophotometer, and the solid was dried and characterized by PXRD and FTIR; the other part of the sample was kept in aqueous suspension, during 10 minutes, until largest particles were decanted, and after that, it was used for determination of electrokinetical (zeta) potential. The measurement of electrokinetical potential was carried out in triplicate at the same temperature of sorption experiments.

\section{Results and discussion}

In Figure 1 presents the sorption isotherms obtained for Asp and Glu. Both isotherms indicate that an increase in temperature of the system results in lower amounts of amino acid removed. For Asp sorption, the maximum amount removed was $2.0 \times 10^{-3}$ mol.g ${ }^{-1}$ and $1.8 \times 10^{-3}$ mol.g $\mathrm{g}^{-1}$ at $298 \mathrm{~K}$ and $310 \mathrm{~K}$ respectively, while for Glu the maximum amount removed was $2.7 \times 10^{-3} \mathrm{~mol} \cdot \mathrm{g}^{-1}$ and $1.6 \times 10^{-3}$ mol.g ${ }^{-1}$.

The lower amount of amino acid removed obtained at $310 \mathrm{~K}$ can be explained considering that with at higher temperature of the system, the higher is the importance of entropy for the system's Gibb's free energy $(\Delta G=\Delta H-$ $\mathrm{T} \Delta \mathrm{S}$ ), thus the role of enthalpy is reduced. Thus, organization of compact aggregates with a larger number of amino acid molecules at the LDH should become more difficult. Moreover, as the experiments were performed in aqueous medium, the interlayer section of the LDH provides an environment energetically most suitable to host hydrophobic molecules. At $298 \mathrm{~K}$ this effect is intensified in favor of Glu intercalation due to its higher hydrophobic character than Asp. Therefore, the more hydrophobic is the amino acid, the more it will be sorbed at the same equilibrium concentration at $298 \mathrm{~K}$ while the opposite trend occurs at $310 \mathrm{~K}$.

At lower aminoacids concentrations, the sorption process does not seem to be influenced by temperature and the amounts of aminoacids removed are approximately the same for all conditions. The LDH reconstruction with both aminoacids seems to be very similar. The regeneration at low aminoacids concentrations occurs predominantly via intercalation of $\mathrm{OH}^{-}$anions from aqueous solution ( $\mathrm{pH}$ 10). As the amino acid concentration increases, a competition between $\mathrm{OH}^{-}$and amino acid takes place with amino acid intercalation. At lower amino acid concentrations, approximately 99\% of Asp or Glu are removed; whereas, at higher amino acid concentration, near the limit of solubility, the extraction rate is approximately $20 \%$. The electrokinetical potential curves related to each isotherm are also very similar. Positives values at low equilibrium concentrations decrease, reaching values as negative as $-6 \mathrm{mV}$, while the aminoacids concentration increase. The profiles of electrokinetical potential curves are in agreement with the respective isotherm profile.

The amount of charge available for removal of anionic species by the calcined $\mathrm{LDH}$ was calculated taking into account the amount of $\mathrm{Al}^{3+}$, and it was found $5.36 \times 10^{-3} \mathrm{~mol}$ of charge $(+1)$ per $\mathrm{g}$ of calcined LDH. Then, $2.68 \times 10^{-3} \mathrm{~mol}$ of Asp or Glu could be removed by anionic exchange. The maximum amount remove (after isotherms) is about $2.7 \times 10^{-3} \mathrm{~mol}$ Glu per $\mathrm{g}$ of $\mathrm{LDH}$ at $298 \mathrm{~K}$. The other values in the corresponding isotherms are lower. 

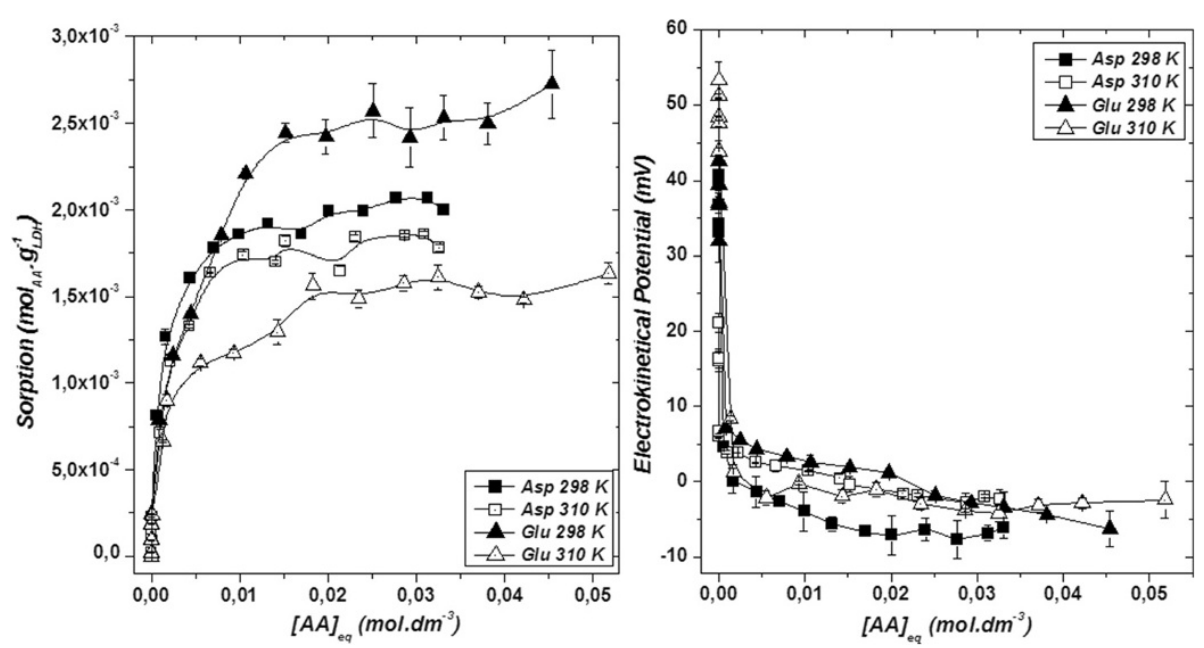

Figure 1 Left: Isotherms; Right: Electrokinetical potential related to the aminoacids sorption.

In Figure 2 are presented results obtained by PXRD and FTIR for the calcined LDH and the solids obtained after sorption experiments. For the calcined $\mathrm{LDH}$, the diffractogram did not give evidence of a lamellar structure, but only peaks assigned to the mixed oxide could be seen. On the other hand, the $\mathrm{LDH}$ regenerated at $\mathrm{pH}$ 10 presented a basal spacing of $7.4 \AA$, which suggests intercalation of $\mathrm{OH}^{-}$anions. The solids regenerated at higher Asp and Glu concentrations presented a basal spacing of 11.4 $\AA$ and $12.2 \AA$, respectively, calculated by Bragg equation. Considering the LDH layer width of 4.8
$\AA$ in addition to the hydrogen bonding space, interlamellar spacing of $6.6 \AA$ and $7.4 \AA$ are then obtained for the interleaved Asp and Glu. This suggests that intercalation occurs with the amino acids aligned parallel to each other and perpendicular to the layers of the LDH (Tronto et al. 2003) although two series of peaks 001 indicating the presence of other anion besides the aminoacids. The FTIR spectra obtained for calcined LDH are characterized by an intense broad band at $3400 \mathrm{~cm}^{-1}$, which is due to $\mathrm{O}-\mathrm{H}$ stretching of the hydroxyl groups and water. The presence of aminoacids can be evidenced by two bands at 1590 and
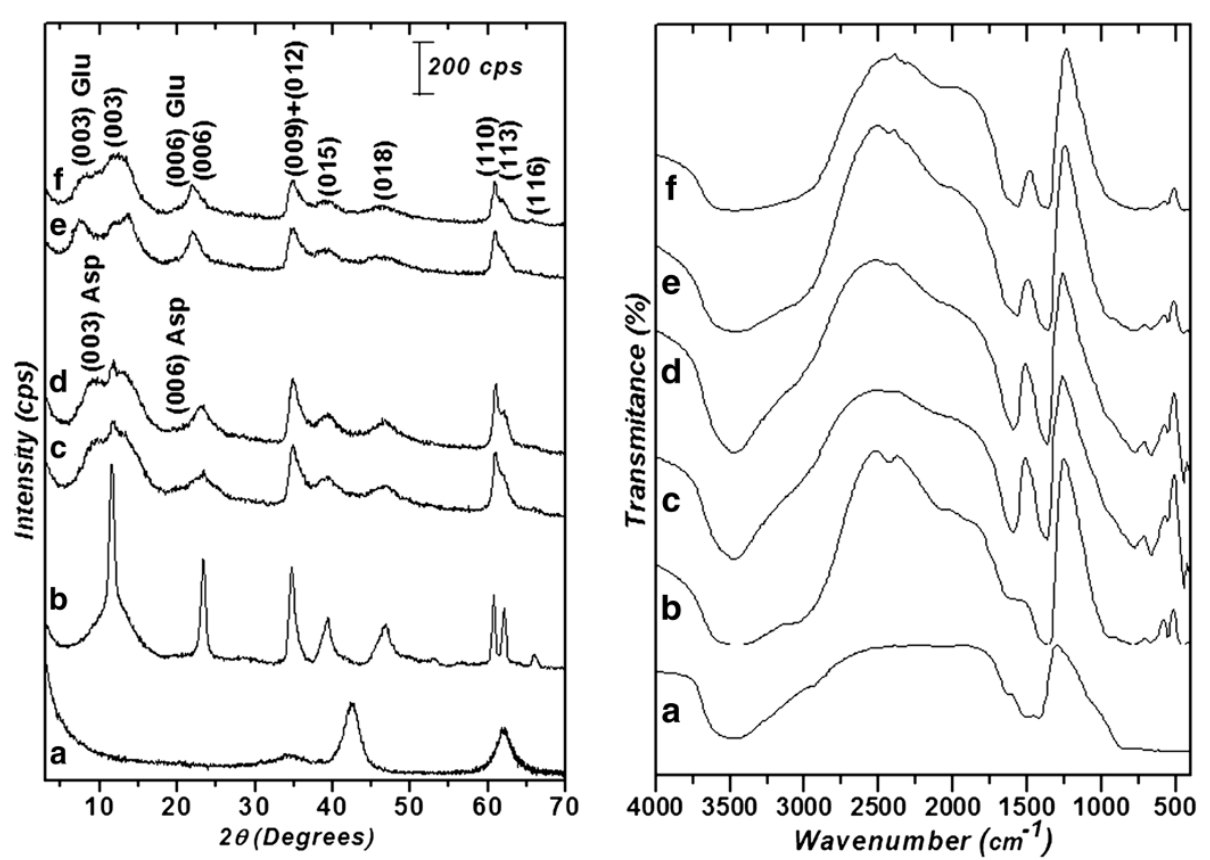

Figure 2 Left: PXRD; Right: FTIR. a) calcined LDH; b) LDH regenerated with $\mathrm{OH}^{-}$anions; c) LDH sorbed with Asp (298 K); d) LDH sorbed with Asp (310 K); e) LDH sorbed with Glu (298 K); f) LDH sorbed with Glu (310 K). 
Table 1 General parameters observed for the material sorbed with Asp and Glu at $298 \mathrm{~K}$ and $310 \mathrm{~K}$

\begin{tabular}{ccccc}
\hline Sample & Medium particle size $(\AA)$ & SSS $\left.\mathbf{~ ( ~}^{\mathbf{2}} \cdot \mathbf{g}^{\mathbf{- 1}}\right)$ & Pore total volume $\left(\mathbf{c m}^{\mathbf{3}} \cdot \mathbf{g}^{\mathbf{- 1}}\right)$ & Average pore diameter $(\AA)$ \\
\hline LDH calcined & - & 191.4 & 0.250 & 52.3 \\
Regenerated with OH & 251.9 & 47.6 & 0.284 & 238.8 \\
Initial area (Asp-298 K) & 248.4 & 51.5 & 0.282 & 219.2 \\
Initial area (Glu-298 K) & 320.3 & 57.5 & 0.284 & 196.7 \\
Last point (Asp-298 K) & 48.3 & 1.7 & 0.010 & 238.9 \\
Last point (Asp-310 K) & 85.5 & 6.7 & 0.021 & 224.6 \\
Last point (Glu-298 K) & 88.3 & 1.6 & 0.006 & 151.2 \\
Last point (Glu-310 K) & 88.2 & 2.2 & 0.009 & 172.9 \\
\hline
\end{tabular}

$1400 \mathrm{~cm}^{-1}$ related to the asymmetric and symmetric stretching of carboxylate group (Fudala et al. 1999; Aisawa et al. 2002; Whilton et al. 1997).

The thickness of the platelets of the materials was also calculated from PXRD using Debye-Scherer method (West 1987). The results presented in Table 1 suggest good restacking of the LDH in water and at low Asp and Glu concentrations. On the other hand, the solids obtained at higher aminoacids concentrations (in the plateau of sorption) presented lower structural organization. Specific surface area (SSA) was determined (Table 1) for all materials are lower than that determined for the calcined material.

SEM images obtained for the LDH before and after aminoacids sorption is presented in Figure 3. The MgAl$\mathrm{CO}_{3}-\mathrm{LDH}$ precursor presents irregular surface with low pororosity and few aggregates is observed (Figure 3a) while the calcined LDH (Figure $3 \mathrm{~b}$ ) presents high porous surface, in agreement with SSA. The images obtained for the material sorbed with Asp (Figure 3c and d) and Glu (Figure $3 e$ and $\mathrm{f}$ ) present white aggregates in surface due to the presence of less conductive organic species. These materials are less porous which also agrees with SSA.

\section{Conclusions}

The results showed that Asp and Glu intercalation by sorption is a process that dependent on the amino acid concentration. At low amino acid concentrations, the LDH is regenerated predominantly with intercalated hydroxyl anions. As the amino acid concentration increases, a competition between the hydroxyl anions and the amino acid

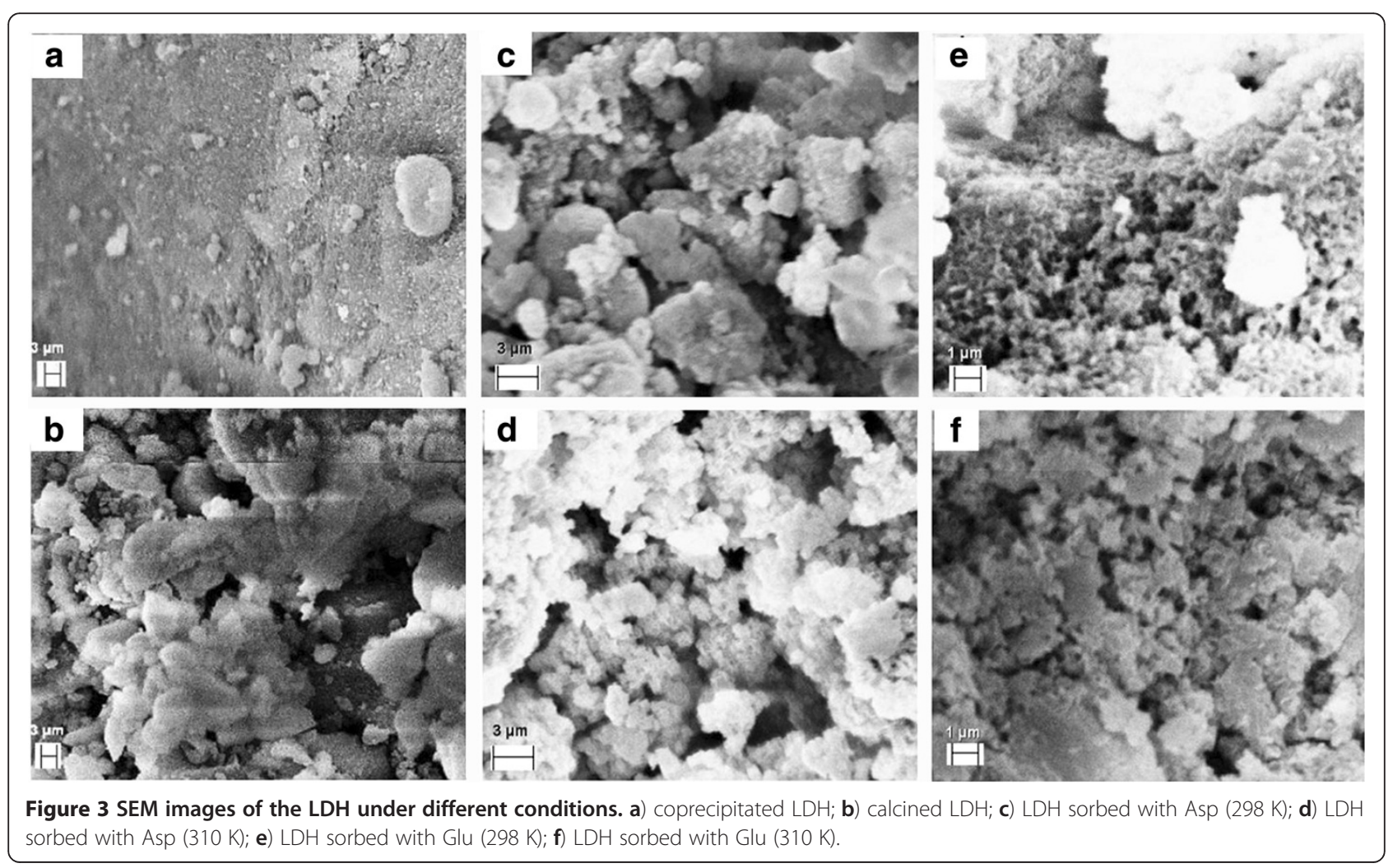


for intercalation in the interlayer domain takes place with amino acid dislocating the equilibrium in favor of Asp or Glu intercalation. The results also suggested that Asp and Glu sorption is a temperature dependent process, with a decrease in the amount of sorbed amino acid with increasing temperature. This effect is more pronounced in the case of Glu, probably due to its higher hydrophobic character, which makes the sorption more difficult in comparison with sorption of Asp at higher temperature. Thus, aminoacids hydrophobicity contributes to sorption: the more hydrophobic is the amino acid, the more it will be sorbed at the same equilibrium concentration at $298 \mathrm{~K}$, while the opposite trend occurs at $310 \mathrm{~K}$.

\section{Competing interests}

The authors declare that they have no competing interests.

\section{Authors' contributions}

FS performed the aminoacids sorption experiments and contributed in both characterization with all techniques and the write up of this manuscript. MJR analyzed the sample with zeta potential measurement and contributed in the write up of this manuscript. The main idea of this manuscript was

structured by JT and JBV. All authors read and approved the final manuscript.

\section{Acknowledgements}

The authors thank the Brazilian agencies CAPES and CNPq for financial support.

Received: 18 October 2012 Accepted: 4 May 2013

Published: 8 May 2013

\section{References}

Aisawa S, Hirahara H, Uchiyama H, Takahashi S, Narita E, Solid State J (2002) Chem 167:152-159

Aisawa S, Kudo H, Hoshi T, Takahashi S, Hirahara H, Umetsu Y, Narita E, Solid State J (2004) Chem 177:3987-3994

Anbarasan R, Lee WD, Im SS (2005) Bull Mater Sci 28:145-149

Cardoso LP, Tronto J, Crepaldi EL, Valim JB (2003) Mol Cryst Liq Cryst 390:49-56

Cardoso LP, Valim JB, Phys J (2004) Chem Solids 65:481-485

Costantino U, Ambrogi V, Nocchetti M, Perioli ML (2008) Microporous Mesoporous Mater 107:149-160

Crepaldi EL, Tronto J, Cardoso LP, Valim JB (2002) Colloids Surf A 211:103-114

Darder M, Aranda P, Ruiz-Hitzky E (2007) Adv Mater 19:1309-1319

Evans DG, Xue DA (2006) Chem Comm 5:485-496

Fudala A, Palinko I, Kiricsi I (1999) J Mol Struct 483:33-37

Kooli F, Depège C, Ennaqadi A (1997) A de Roy and J. P. Besse. Clays Clay Miner 45:92-98

Ohtsubo K, Suzuki K, Yasui Y, Kasumi T, Food Comp J (2005) Anal 18:303-316

Reichle WT, Kang SY, Everhardt DS (1986) J Catal 101:352

Shih IL, Van YT (2001) Bioresour Technol 79:207-225

Takehira K, Shishido T (2007) Catal Surv Asia 11:1-30

Takehira K, Kawabata T, Shishido S, Murakami K, Ohi T, Shoro D, Honda M, Takaki K (2005) J Catal 231:92-104

Tronto J, Cardoso LP, Valim JB, Marchetti JM, Bentley MVB (2003) Mol Crist Liq Crist 390:79-89, Part 2

Tronto J, dos Reis MJ, Silverio F, Balbo VR, Marchetti JM, Valim JB, Phys J (2004) Chem Solids 65:475-480

Velu S, Suzuki K, Vijayaraj M, Barman S, Gopinath CS (2005) Appl Catal B 55:287-299

West AR (1987) Solide State Chemistry and its Applications. J. Wiley, Chichester Whilton NT, Vickers PJ, Mann S (1997) J Mater Chem 7:1623-1629

Zhu MX, Li YP, Xie M, Xin HZ (2005) J Hazard Mater 120:163-171

doi:10.1186/2193-1801-2-211

Cite this article as: Silvério et al:: Sorption of aspartic and glutamic aminoacids on calcined hydrotalcite. SpringerPlus 2013 2:211.

\section{Submit your manuscript to a SpringerOpen ${ }^{\circ}$ journal and benefit from:}

- Convenient online submission

- Rigorous peer review

- Immediate publication on acceptance

- Open access: articles freely available online

- High visibility within the field

- Retaining the copyright to your article

Submit your next manuscript at $\downarrow$ springeropen.com 